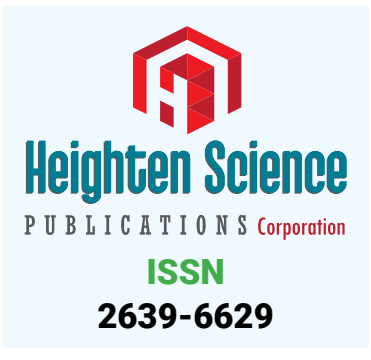

*Address for Correspondence: Massimo Leggio, MD, PhD, Department of Medicine and Rehabilitation, Cardiac Rehabilitation Operative Unit, San Filippo Neri HospitalSalus Infirmorum Clinic, Via della Lucchina 41, 00135 Rome, Italy, Tel: +3906302511; Fax: +390630811972; Email: mleggio@libero.it

Submitted: 19 December 2016

Approved: 19 January 2017

Published: 21 January 2017

Copyright: @ 2017 Lombardi, et al. This is an open access article distributed under the Creative Commons Attribution License, which permits unrestricted use, distribution, and reproduction in any medium, provided the original work is properly cited.

\title{
Sex Differences in Hypertension: A Question worth Asking?
}

\author{
Mario Lombardi ${ }^{1}$, Paolo Severi ${ }^{2}$, Andrea Mazza ${ }^{3}$, Maria Grazia \\ Bendini $^{3}$, Elisa Caldarone ${ }^{1}$, Massimo Armeni ${ }^{4}$, Stefania \\ D'Emidio ${ }^{1}$ and Massimo Leggio'* \\ 'Physical Medicine and Neurorehabilitation Operative Unit, Salus Infirmorum Clinic, Rome, \\ Italy \\ 2Department of Medicine and Rehabilitation, Cardiac Rehabilitation Operative Unit, San Filippo \\ Neri Hospital-Salus Infirmorum Clinic, Rome, Italy \\ ${ }^{3}$ Cardiology Division, Santa Maria della Stella Hospital, Orvieto, Italy \\ ${ }^{4}$ Institute for Craniosacral Therapies, Norma, Italy
}

\section{SHORT COMMUNICATION}

Hypertension is a complex disorder involving multiple organ systems and the primarily modifiable risk factor for heart disease, which is the leading cause of death among both men and women in the World. Although both men and women develop hypertension, distinct gender differences in the incidence and severity of hypertension are well established where men have a higher incidence of hypertension compared with women of the same age until the sixth decade of life [1,2]. Despite gender differences in human hypertension, the treatment guidelines do not differ by gender [3]. Even if the causes of hypertension are complex and are related to genetic factors, lifestyle, diet structure, and environmental factors including air pollution [4], coupled with the potential determinants of hypertension, sex differences in hypertensionwhich exist in human populations-are attributed to both biological and behavioural factors. The biological factors include sex hormones, chromosomal differences, and other biological sex differences that are protective against hypertension in women. These factors become prominent in adolescence and persist through adulthood until women reach menopause. Behavioural risk factors for hypertension include high body mass index, smoking, and low physical activity.

The recent National Health and Nutrition Examination Survey study examined ageadjusted awareness, treatment, and blood pressure control rates among hypertensive men and women from 2003 to 2004 through 2011 to 2012 [1], with encouraging results. Awareness of hypertension increased in both men and women during this time period, with the greatest increase in awareness reported in women. Although women were less aware of their hypertension at the beginning of the study, they surpassed men's awareness by the end of the study. In addition, the percent of individuals treated for their hypertension increased from 2003 to 2012, and again this increase was greater in women [1]. Most importantly, however, the increase in treatment was associated with an increase in the percent of hypertensive patients who achieved blood pressure controlled to the recommended levels from $\approx 43 \%$ to $49 \%$ in men and from $\approx 37 \%$ to $56 \%$ among women [1]. Although this reflects a large improvement in the numbers of individuals with controlled blood pressure, this still leaves almost half of the hypertensive population at increased risk for adverse cardiovascular events [1]. The 
authors further examined the numbers of men and women with optimal blood pressure, prehypertension, stage I hypertension, and stage II hypertension over the same time frame (2003-2012). Interestingly, the percent of women with prehypertension increased from $\approx 25 \%$ to $37 \%$, whereas the percent of men defined as prehypertensive remained constant at $\approx 29 \%$. In contrast, more men have stage 1 hypertension than women. The incidence of stage 2 hypertension was relatively comparable between the sexes in 2012 ( $\approx 11 \%$ versus $13 \%$ in men and women, respectively), although a decrease in the number of women with stage 2 hypertension since $2003(\approx 13 \%$ versus $23 \%$ in men versus women) was observed [1]. These findings are indicative of 2 noteworthy trends in hypertension. First, women are more likely to be prehypertensive than men. Second, we are making progress in the treatment and control of hypertension, but we still have a long ways to go. For this study, controlled hypertension was defined as systolic blood pressure of $<140 \mathrm{~mm} \mathrm{Hg}$ and diastolic blood pressure of $<90 \mathrm{~mm} \mathrm{Hg}$, which raises 2 important questions: -1 - is this an adequate decrease in blood pressure to allow for optimal decreases in cardiovascular disease risk? -2- Should controlled blood pressure be defined the same in both genders?

The most recent recommendations for the management of hypertension were published in 2013-2014: although there are age-dependent recommendations for blood pressure goals, the guidelines remain the same irrespective of gender, despite the abundance of evidence supporting sex and gender differences in hypertension [3,5]. The recent findings of SPRINT (Systolic Blood Pressure Intervention Trial) suggested that more aggressive blood pressure control results in improved health outcomes [6]. This was a multicenter, randomized clinical trial of patients aged $\geq 75$ years randomized to an intensive treatment group (systolic blood pressure target of $<120 \mathrm{~mm} \mathrm{Hg}$ ) or standard treatment group (systolic blood pressure target of $<140$ $\mathrm{mm} \mathrm{Hg}$ ). Individuals in the intensive treatment group had a $\approx 25 \%$ greater reduction in cardiovascular events compared with those in the standard treatment, supporting a beneficial effect for aggressive blood pressure control. However, whether there are gender-specific implications for SPRINT remains unknown. Although SPRINT planned to clarify optimal blood pressure management in both men and women, female enrolment was only $\approx 36 \%$ (77 women in the intensive treatment group versus 166 men; 89 women in the standard treatment group versus 230 men), the number of cardiovascular events in enrolled women was below that seen in the general population, and the study was terminated early because of the clear benefits of more aggressive blood pressure control among men [6,7]. As a result, none of the outcome differences in women reached statistical significance, and no conclusions could be drawn on the effectiveness of intensive blood pressure control in women.

The potential for more aggressive blood pressure control to improve cardiovascular outcomes becomes of even greater interest in case of gender differences in the relationship between elevations in blood pressure and impact of hypertension in general on end-organ damage. Boggia et al. [8] assessed and compared the absolute and relative risks associated with conventional office and ambulatory blood pressure measurements and cardiovascular complications in a large cohort of men $(n=4960)$ and women $(n=4397)$ from the general population of 11 different countries. In both genders, 24-hour ambulatory and conventional daytime and nighttime systolic blood pressures were significant predictors of cardiovascular events. As reported previously, women were at lower risk of cardiovascular events than men in this international cohort followed up for a median of 11.2 years. Of note, although the study confirmed the lower incidence of total, cardiovascular, and noncardiovascular mortality and of cardiovascular morbidity in women and the better cardiovascular risk profile of women, they do not appear to be underdiagnosed or undertreated for hypertension. Indeed, the percentage of untreated persons in this cohort was lower among women than men, and the number of treated and adequately controlled cases was slightly better 
in women. Thus, labelling of women as being in a low cardiovascular risk group does not appear to have a major impact on their clinical management [8]. However, when assessing the association of cardiovascular complications with 24-hour ambulatory blood pressure and night time blood pressure, the authors found that the relation of all cardiovascular events and stroke and cardiac events with night time blood pressure were much steeper in women. Thus, the percentage of preventable cardiovascular events in relation to night time systolic blood pressure but not daytime systolic blood pressure was significantly greater in women than in men. These results therefore suggest that although women are at low cardiovascular risk, there is a clear potential for improvement in the assessment of their cardiovascular risk by using ambulatory blood pressure rather than conventional office blood pressure and by analyzing more carefully the night time blood pressure [8]. In fact, women had a significantly higher risk of a cardiovascular event in relation to 24-hour ambulatory systolic blood pressure and night time systolic blood pressure compared with men, and hence women exhibited a stronger increase in risk of a cardiovascular event with increases in blood pressure than men and had a higher proportion of potentially preventable events. These findings suggest that women would have greater cardiovascular benefits from decreases in blood pressure and imply that optimal blood pressure is lower in women than in men [8].

This is further supported by a prospective study of 3344 subjects (1626 women), which found a steeper relationship between higher ambulatory blood pressure and cardiovascular disease risk in women than in men [9]: in this latter study Hermida et al. concluded that the optimal outcome-based blood pressure threshold for men was 135/85 mm Hg during the day and 120/70 mm Hg during the night, compared with 125/80 mm Hg during the day 110/65 mm Hg during the night for women. In contrast, a separate meta-analysis of 5018 people (2843 women) provided by Nomura et al. examined the relationship between conventional home blood pressure measurements and 10-year cardiovascular risks in men and women and did not find significant differences between the genders [10]. This discrepancy may be because of the different methods used to measure blood pressure (frequent ambulatory blood pressure measurements compared with isolated conventional blood pressure measurements) or the time of day blood pressure was recorded. Regardless, the data provide sufficient evidence to call into the matter current guidelines recommending the same level of blood pressure control in men and women and underscores the importance of continued research.

Recent advances in basic science research have identified several possible mechanisms responsible for the observed sex differences in hypertension, and recent publications provided consistent results implicating the divergent role of the immune system in hypertensive males and females [11-16]. It can be hypothesized that the greater anti-inflammatory immune profile in females during hypertension may act as a compensatory mechanism to limit increases in blood pressure compared with males who exhibit a more proinflammatory immune profile. However, the mechanisms underlying these changes in immune cells in hypertensive males and females are not yet well understood. One possible mediator is the angiotensin type 2 receptor, which has previously been shown to have greater activity in females, and recent studies indicate that angiotensin type 2 receptor promotes an anti-inflammatory immune profile [17-20]. Further research to elucidate the complex role of the immune system in hypertension in both sexes is critical and may aid in discovering new therapeutic pathways to better control blood pressure in both sexes.

In conclusion, the existence of sex differences in hypertension is a really tough question that strongly worth asking. A growing body of evidences provide whole confirmation that current guidelines recommending the same therapeutic approach 
and level of blood pressure control in men and women should be challenged. Further research should explore the complex mechanisms explaining the differences between hypertensive males and females and suggest optimal methods and strategies to improve management of hypertension in both sexes.

\section{REFERENCES}

1. Yoon SS, Gu Q, Nwankwo T, Wright JD, Hong Y, Burt V. Trends in blood pressure among adults with hypertension: United States, 2003 to 2012. Hypertension. 2015; 65: 54-61. Ref.: https://goo.gl/yliJHD

2. Mozaffarian D, Benjamin EJ, Go AS, Arnett DK, Blaha MJ, et al. American Heart Association Statistics Committee; Stroke Statistics Subcommittee. Heart Disease and Stroke Statistics-2016 Update: A Report from the American Heart Association. Circulation. 2016; 133: e38-360. Ref.: https://goo. gl/1jc09T

3. James PA, Oparil S, Carter BL, Cushman WC, Dennison-Himmelfarb C, et al. 2014 evidencebased guideline for the management of high blood pressure in adults: report from the pane members appointed to the Eighth Joint National Committee (JNC 8). JAMA. 2014; 311: 507-520. Ref.: https://goo.gl/7jo7U4

4. Caldarone E, Lombardi M, Severi P, Leggio M. Ambient Air Pollution and Hypertension: A Relationship that Strikes Around the Clock. Arch Clin Hypertens. 2016; 1: 044-045.

5. Mancia G, Fagard R, Narkiewicz K, Redon J, Zanchetti A, et al. 2013 ESH/ESC guidelines for the management of arterial hypertension: the Task Force for the Management of Arterial Hypertension of the European Society of Hypertension (ESH) and of the European Society of Cardiology (ESC). Eur Heart J. 2013; 34: 2159-2219. Ref.: https://goo.gl/NmBOr1

6. Williamson JD, Supiano MA, Applegate WB, Berlowitz DR, Campbell RC, et al. SPRINT Research Group Intensive vs Standard Blood Pressure Control and Cardiovascular Disease Outcomes in Adults Aged $\geq 75$ Years: A Randomized Clinical Trial. JAMA. 2016; 315: 2673-2682. Ref.: https://goo.gl/7PHO9|

7. Wenger NK, Ferdinand KC, Bairey Merz CN, Walsh MN, Gulati M, et al. American College of Cardiology Cardiovascular Disease in Women Committee. Women, Hypertension, and the Systolic Blood Pressure Intervention Trial. Am J Med. 2016; 129: 1030-1036. Ref.: https://goo.gl/5fMCIN

8. Boggia J, Thijs L, Hansen TW, Li Y, Kikuya M, et al. International Database on Ambulatory blood pressure in relation to Cardiovascular Outcomes Investigators. Ambulatory blood pressure monitoring in 9357 subjects from 11 populations highlights missed opportunities for cardiovascular prevention in women. Hypertension. 2011; 57: 397-405. Ref.: https://goo.gl/926nkw

9. Hermida RC, Ayala DE, Mojón A, Fontao MJ, Chayán L, et al. Differences between men and women in ambulatory blood pressure thresholds for diagnosis of hypertension based on cardiovascular outcomes. Chronobiol Int. 2013; 30: 221-232. Ref.: https://goo.gl/5JFIDa

10. Nomura K, Asayama K, Thijs L, Niiranen TJ, Lujambio I, et al. International Database of Home Blood Pressure in Relation to Cardiovascular Outcome Investigators. Thresholds for conventional and home blood pressure by sex and age in 5018 participants from 5 populations. Hypertension. 2014; 64: 695-701. Ref.: https://goo.gl/TjwqEp

11. Ji H, Zheng W, Li X, Liu J, Wu X, et al. Sex-specific T-cell regulation of angiotensin II-dependent hypertension. Hypertension. 2014; 64: 573-582. Ref.: https://goo.gl/XzrGa5

12. Pollow DP, Uhrlaub J, Romero-Aleshire MJ, Sandberg K, Nikolich Zugich J, et al. Sex differences in T-lymphocyte tissue infiltration and development of angiotensin II hypertension. Hypertension. 2014; 64: 384-390. Ref.: https://goo.gl/Sj4moH

13. Sandberg K, Ji H, Hay M. Sex-specific immune modulation of primary hypertension. Cell Immunol. 2015; 294: 95-101. Ref.: https://goo.gl/IW8FMp

14. Meng $\mathrm{X}$, Yang J, Dong M, Zhang $\mathrm{K}$, Tu E, et al. Regulatory T cells in cardiovascular diseases. Nat Rev Cardiol. 2016; 13: 167-179. https://goo.gl/qrqWA1

15. Crislip GR, Sullivan JC. T-cell involvement in sex differences in blood pressure control. Clin Sci (Lond). 2016; 130: 773-783. Ref.: https://goo.gl/u7UP05

16. Tipton AJ, Sullivan JC. Sex differences in T cells in hypertension. Clin Ther. 2014; 36: 1882-1900. Ref.: https://goo.gl/OpdLYQ

17. Chappell MC, Marshall AC, Alzayadneh EM, Shaltout HA, Diz DI. Update on the Angiotensin converting enzyme 2-Angiotensin (1-7)-MAS receptor axis: fetal programing, sex differences, and intracellular pathways. Front Endocrinol (Lausanne). 2014; 4: 201. Ref.: https://goo.gl/np1brf 
18. Pessôa BS, Slump DE, Ibrahimi K, Grefhorst A, van Veghel R, et al. Angiotensin II type 2 receptorand acetylcholine-mediated relaxation: essential contribution of female sex hormones and chromosomes. Hypertension. 2015; 66: 396-402. Ref.: https://goo.gl/ECG734

19. Hilliard LM, Nematbakhsh M, Kett MM, Teichman E, Sampson AK, et al. Gender differences in pressure-natriuresis and renal autoregulation: role of the Angiotensin type 2 receptor. Hypertension. 2011; 57: 275-282. Ref.: https://goo.gl/pb0NwM

20. Zhang JD, Patel MB, Song YS, Griffiths R, Burchette J, et al. A novel role for type 1 angiotensin receptors on $\mathrm{T}$ lymphocytes to limit target organ damage in hypertension. Circ Res. 2012; 110: 1604-1617. Ref.: https://goo.gl/5JKA2M 